\title{
BM] Global Health Conference equity in global health: a systematic review of factors impacting LMIC representation at global health conferences
}

\author{
Lotta Velin (D) ,,2 Jean-Wilguens Lartigue (D) ,,3 Samantha Ann Johnson (D) , \\ Anudari Zorigtbaatar (D) ,1,5 Ulrick Sidney Kanmounye, ${ }^{1,6}$ Paul Truche, ${ }^{1,7}$ \\ Michelle Nyah Joseph ${ }^{1,8}$
}

To cite: Velin L, Lartigue J-W, Johnson SA, et al. Conference equity in global health: a systematic review of factors impacting LMIC representation at global health conferences. BMJ Global Health 2021;6:e003455. doi:10.1136/ bmjgh-2020-003455

Handling editor Senjuti Saha

Received 15 July 2020

Revised 4 December 2020

Accepted 9 December 2020

Check for updates

(C) Author(s) (or their employer(s)) 2021. Re-use permitted under CC BY-NC. No commercial re-use. See rights and permissions. Published by BMJ.

For numbered affiliations see end of article.

\section{Correspondence to} Dr Michelle Nyah Joseph; Michelle_Joseph@hms.harvard. edu

\section{ABSTRACT}

Introduction Global health conferences are important platforms for knowledge exchange, decision-making and personal and professional growth for attendees. Neocolonial patterns in global health at large and recent opinion reports indicate that stakeholders from lowand middle-income countries (LMICs) may be underrepresented at such conferences. This study aims to describe the factors that impact LMIC representation at global health conferences.

Methods A systematic review of articles reporting factors determining global health conference attendance was performed using the Preferred Reporting Items for Systematic Reviews and Meta-Analyses guidelines. Articles presenting conference demographics and data on the barriers and/or facilitators to attendance were included. Articles were screened at title and abstract level by four independent reviewers. Eligible articles were read in full text, analysed and evaluated with a risk of bias assessment.

Results Among 8765 articles screened, 46 articles met inclusion criteria. Thematic analysis yielded two themes: 'barriers to conference attendance' and 'facilitators to conference attendance'. In total, 112 conferences with 254601 attendees were described, of which $4 \%$ of the conferences were hosted in low-income countries. Of the 98302 conference attendees, for whom affiliation was disclosed, 38167 (39\%) were from LMICs.

Conclusion 'Conference inequity' is common in global health, with LMIC attendees under-represented at global health conferences. LMIC attendance is limited by systemic barriers including high travel costs, visa restrictions and lower acceptance rates for research presentations. This may be mitigated by relocating conferences to visa-friendly countries, providing travel scholarships and developing mentorship programmes to enable LMIC researchers to participate in global conferences.

\section{INTRODUCTION}

Global health conferences are forums of decision making, knowledge exchange, networking and personal development, pivotal to the field. ${ }^{12}$ Health conferences provide opportunities that are highly beneficial for career development ${ }^{3-6}$ and attendees from low- and middle-income countries (LMICs), regions disproportionately burdened by disease, unquestionably have much to contribute and to gain from active participation at these conferences. However, inequities in conference attendance, raised in recent opinion pieces, have drawn light to an area that requires critical attention. ${ }^{7-11}$

The majority of the global disease burden occurs in LMICs where $84 \%$ of the world's population resides. ${ }^{12}$ Yet, decision making and research on global health are dominated by high-income countries (HICs). This parallels a neocolonial trend, with the economic, political and cultural influence of former colonial powers still shown ${ }^{13}$ in the under-representation of local authors in global health research, especially in the first and senior author position, on editorial boards, ${ }^{14-16}$ and in the fact that $85 \%$ of headquarters of global health organisations are located in the global north. ${ }^{17}$ Therefore, it is not surprising that the majority of global health conferences follow the same geographical constellation. The skewness of these locations to the 'global north' is undeniably linked to a colonial history which continues to affront today as a complex multitude of barriers to equity in global health,. ${ }^{13}{ }^{18-22}$ Our preliminary study shows that for the annual Consortium of Global Health in the USA, countries with higher US visa rejection rates had lower number of representative speakers $(p=0.04)$ and for each $10 \%$ increase in the US visa rejection rate, the number of speakers decreased by $23 \%(\mathrm{p}=0.01),{ }^{23}$ Understanding the importance of such barriers, in the context 
Summary box

What is already known?

- The majority of the global disease burden exists in low- and middleincome countries (LMICs), yet decision making in global health policy and research is often led by high-income countries (HICS).

- Global health conferences are often located in and managed by HIC institutions.

- Factors impacting global health career opportunities, such as conference attendance, exist at both the individual (geographical and socioeconomic) and organisational (funding streams, political factors, historical/colonial) level.

What are the new findings?

- Based on the definition of conference equity as 'attainment of an equitable level of attendee active engagement, influence and access to a conference regardless of country of origin, location, available funds or affiliation, through the mitigation of known barriers and enhancement of efficacious facilitators', the literature on global health conference attendance and the associated barriers and facilitators is limited and heterogeneous.

- This systematic review includes 46 articles describing 112 unique conferences with 254601 attendees from the past three decades. Of these conferences, only $4 \%$ were hosted in low-income countries and $39 \%$ of attendees were from LMICs.

- LMIC attendees most commonly perceived limited speaking opportunities at global health conferences, indicating limited opportunities for active and meaningful participation. The primary factor identified with potential for improving conference equity included relocation to LMICs or 'visa-friendly countries'.

\section{What do the new findings imply?}

- Global health conferences, in their current model, are not equitable. The underrepresentation of LMIC attendees is a loss to the global health discourse.

- Conference attendees from LMICs face systemic barriers in travelling to and participating in global health conferences, with lowincome country attendees being particularly vulnerable to exclusion.

- Global health conferences should be held in visa-friendly countries, provide travel scholarships, and offer mentorship programmes to promote attendance by LMIC researchers and stakeholders.

of global health conference attendance, and equally the strategies implemented to facilitate attendance is an intentional first step towards establishing 'conference equity'. We define 'conference equity' as: 'attainment of an equitable level of attendee active engagement, influence and access to a conference regardless of country of origin, location, available funds or affiliation, through the mitigation of known barriers and enhancement of efficacious facilitators'.

This study aimed to describe the factors that impact LMIC representation at global health conferences.

\section{METHODS}

\section{Defining global health}

Out of the multiple definitions for global health, ${ }^{24-26}$ we selected one by Koplan et al: 'An area of study, research and practice that places a priority on improving health and achieving equity in health for all people worldwide, ${ }^{27}$ as the definition most applicable to this study. This definition includes all the primary factors deemed essential to global health, including health equity and global conceptualisation. Additionally, the majority of the secondary factors are also detailed, ${ }^{24}$

\section{Hypothesis}

Using our definition of conference equity, we hypothesised that the majority of global health conferences would be located in HICs; the proportion of LMIC attendees would be higher when held in an LMIC. We further hypothesised that financial subsidies to LMIC attendees increase their participation.

\section{Search strategy and data sources}

A systematic review of articles reporting inequities in global health conference attendance was performed using the Preferred Reporting Items for Systematic Reviews and Meta-Analyses guidelines. ${ }^{28}$ The search strategy (online supplemental appendix 1) was developed in collaboration with and approved by an information specialist (SAJ). A comprehensive, reproducible search from the date of inception to 12 February 2020 of 7 electronic bibliographic databases: Medline, Medline Daily, Medline EPub Ahead of Print and InProces, and Other Non-Indexed Citations from OVID, Embase, PsycINFO, CINAHL, Scopus and Web of Science. Hand searches of African Journals Online Library, WHO Library Database and grey literature were undertaken. All included articles were handsearched for additional articles to be included in the review and collaborative partners were consulted for expert opinion in identifying additional literature.

To identify relevant grey literature, the search terms 'Global Health', 'Conference' and 'Participation' were entered into the Google search engine with file extensions '.com', '.org' and 'un.org'. The first 10 pages were screened to identify publications related to conference equity. To ensure the capture of a wide array of publications, both conference reports, and written presentations were included. Results were imported into EndNote and combined with the search results from the electronic databases. All duplicates were removed.

\section{Selection and appraisal of documents}

Inclusion criteria

Inclusion criteria (online supplemental appendix 2) consisted of points of interest (barriers or facilitators), setting (global health conferences), and population (attendees). We considered facilitators as any action or policy that mitigated the barriers to attending global health conferences. All study designs (qualitative, quantitative randomised experimental, quantitative nonrandomised controlled, quantitative observation and mixed methods) were included. Books and book chapters, reports, commentaries, letters, editorials published in academic journals, dissertations and conference proceedings were also included. 


\section{Exclusion criteria}

Papers that did not specify the location of a conference and did not include data on barriers or facilitators to attending global health conferences were excluded (online supplemental appendix 2). Articles in nonacademic journals such as daily newspapers describing events related to visa rejections were not included.

\section{Article selection}

All articles were screened using Covidence at a title and abstract level by four study members (LV, J-WL, USK and AZ), who randomly divided the papers so that two independent study members reviewed each article. At the end of the initial screening, all conflicts were discussed by the two investigators who had read the title and abstract. If the conflict could not be resolved between the two, a third study member from the screening group made the final decision. All articles included through the title and abstract screen were then reviewed at full-text-level by two independent study members ( $\mathrm{LV}$ and J-WL), using the inclusion and exclusion criteria previously agreed on. All conflicts were resolved between the two reviewers.

\section{Data extraction and analysis}

All eligible full-text articles were read and analysed by two study members (LV and J-WL). For articles with missing information about the conference (eg, the total number of attendees or conference objectives), the conference website was consulted for information retrieval. Two independent reviewers (LV and J-WL) performed a risk of bias assessment using the GRADE approach. ${ }^{23}$ To our knowledge, no guidelines or validated framework exists to address inequities in conference attendance. We used a bottom-up thematic analysis approach to design a conceptual framework. ${ }^{29}$ All relevant data were extracted and then merged in conceptually related variables into subthemes. Similar variables were categorised under the same theme, which underwent thematic analysis and descriptive statistics. ${ }^{29}$ The World Bank Income Country Group classification system and the WHO regions were used to geographically classify countries. ${ }^{30} 31$

\section{Risk of bias assessment and grading of evidence}

We were unable to identify an appropriate risk of bias assessment model that explicitly fit our aim, and therefore, we used the Grading of Recommendations, Assessment, Development and Evaluations (GRADE) approach, ${ }^{32}$ as it was considered the broadest. Included articles were assessed for risk of bias, even though some of them (opinion pieces, eg) were expected to bear substantial bias by their nature. Therefore, we applied an adapted GRADE approach to all included articles, separated by study type.

Inconsistency was defined as difference in outcome (attendance at global health conferences) based on measures to mitigate barriers through facilitators. Potential sources of indirectness were significant variations in the themes addressed (eg, variables not fitting the two themes) or lack of specification of the population, conference, barriers and/or facilitators and outcomes (attendance). Imprecision was defined as lack of evidence supporting the effect of identified barriers and facilitators on attendance by LMIC attendees. Publication bias was defined as the systematic overerestimation or underestimation of the impact of barriers or facilitators on attendance due to selective publication.

\section{RESULTS}

\section{Search results}

In total, 13989 articles, of which 8765 were unique, were found in the academic database searches (figure 1). An additional 24 papers were added from hand searches (n=18, 1 February 2020, 5 May 2020), grey literature (n=3, 1 February 2020), and through expert opinion $(\mathrm{n}=4,31$ March 2020). At title and abstract level, 8769 articles were screened in Covidence, of which 8680 were excluded. Eighty-nine articles were assessed as full texts, of which 43 were excluded due to ineligibility. In the final review, 46 articles were included.

\section{Quality of evidence}

Stratifying by study type, the evidence for each theme is very low (table 1). This infers that there is limited supporting evidence demonstrating barriers and facilitators impact attendance at global health conferences.

\section{Article characteristics}

Of the included articles, 17 were peer-reviewed articles $(37 \%)$ and 29 were other publications (63\%) (table 2). The peer-reviewed journal articles included nine retrospective studies $(20 \%)$, four descriptive studies $(8.7 \%)$, two scientific abstracts $(4.3 \%)$, one scientific letter $(2.2 \%)$ and one mixed-methods study (2.2\%). Non-peerreviewed articles included conference reports $(n=21$, $46 \%)$, opinion pieces $(n=7,15 \%)$ and one scientific newsletter $(n=1,2.2 \%)$. Of the 25 articles with a first author with a country affiliation, seven (28\%) articles had a first author with an LMIC affiliation. Year of publication ranged from 1997 to 2019 with the median year being 2014.

\section{Conference characteristics}

The 46 eligible articles described 112 unique conferences that took place between 1997 and 2019 (online supplemental appenidx 4). The conferences took place in 38 countries from all six WHO regions (figure 2). Of the 112 conferences, $71 \%$ took place in HICs, $26 \%$ in MICs and 4\% in LICs. The most commonly reported host countries were USA $(n=35,31 \%)$, Canada $(n=8$, $7 \%)$ and South Africa $(n=7,6 \%)$. LMIC host countries included South Africa $(n=7,6 \%)$, Thailand $(n=3,3 \%)$, China $(n=3,3 \%)$, Egypt $(n=3,3 \%)$, Mexico $(n=2,2 \%)$, India $(n=2,2 \%)$, Brazil $(n=1,1 \%)$, Serbia and Montenegro $(n=1,1 \%)$, Malaysia $(n=1,1 \%)$ Sri Lanka $(n=1$, $1 \%)$, Colombia $(n=1,1 \%)$, Venezuela $(n=1,1 \%)$, Ghana $(n=1,1 \%)$, Senegal $(n=1,1 \%)$, Togo $(n=1,1 \%)$, Congo 


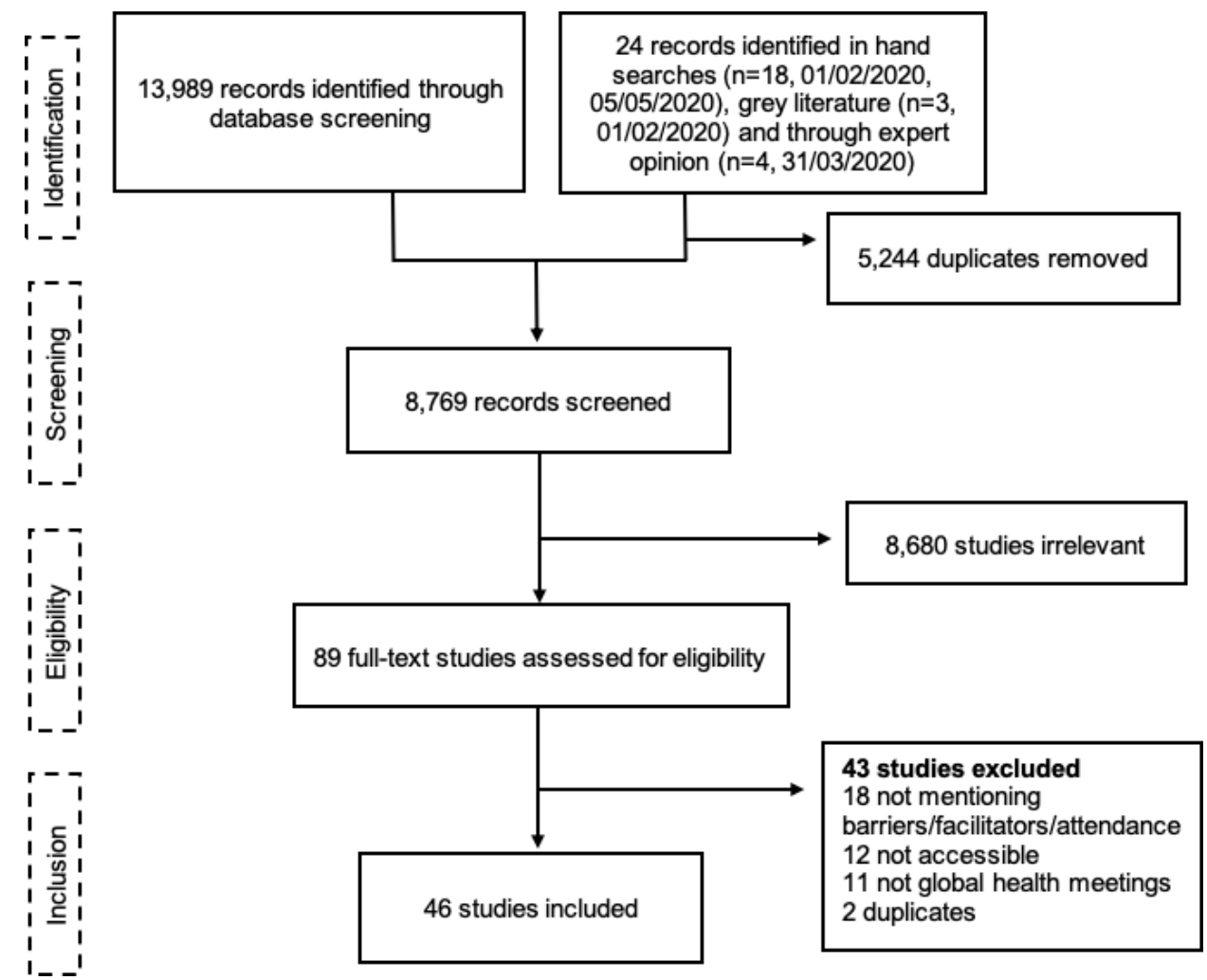

Figure 1 PRISMA flow chart for the systematic review. PRISMA, Preferred Reporting Items for Systematic Reviews and MetaAnalyses.

$(\mathrm{n}=1,1 \%)$, Democratic Republic of Congo $(\mathrm{n}=1,1 \%)$, Tanzania $(n=1,1 \%)$ and Russia $(n=1,1 \%)$. The most common global health field was HIV/AIDS $(n=19$, $41 \%)$, followed by overarching global health $(n=6,13 \%)$, oncology $(n=4,8.7 \%)$ and health systems research $(n=4$, $8.7 \%)$. More than half of the conferences $(n=27,59 \%)$ reported the number of attendees, together making up a total of 254601 attendees. The median number of conference attendees was 5476 (3378-14 022) per conference. Of the conferences that reported the number of countries represented and/or the number of HIC/LMIC attendees, the median number of countries per conference was 136 (118.25-163) and the proportion of LMIC attendees was $39 \%(\mathrm{n}=38167)$.

Conference attendee demographics (age, gender, ethnicity and institutional affiliation (non-governmental organisation, academia, government) ) were discussed in 25 articles. $^{102233-57}$ Women were in the minority in 10/15 (67\%) conferences that provided gender demographics, ${ }^{35} 37$ 39-41 $43444649-5357$ and the age groups $<25$ years and $>50$ years were also constituted minorities in $8 / 8$ conferences presenting data on age groups, with the $<25$ years age group making up approximately 5\%-10\% of conference participants. ${ }^{35} 37394043465758$ In two articles, postconference survey responses highlighted demographic diversity as a benefit of the conference and requested further representation of minority groups such as women, indigenous groups, and LMIC stakeholders. ${ }^{36} 39$
Thematic analysis

Thematic analysis of the articles yielded two themes (1) barriers and (2) facilitators to conference equity, with five and four subthemes, respectively (table 2, figure 3).

\section{Barriers}

Barriers to conference attendance for LMIC attendees were described in 38 articles (83\%). . $^{70} 22$ 33-38 $404345-4749-515355-5759-71$ We organised the identified barriers into five categories: limited speaking opportunities, financial barriers, visa restrictions, political barriers and racism/discrimination.

\section{Limited speaking opportunities}

Limited speaking opportunities, defined as not being selected for presentations or speaking roles at conferences, was cited as a barrier to active participation in 26 articles. $^{33-36} 384043-4749515556$ 59-62 65 67-70 72 For the 2009 International AIDS Society (IAS) Conference in South Africa, Uganda and Nigeria were two of the top five countries, together with USA, Australia and India, that submitted a high number of abstracts, 167 and 228, respectively. ${ }^{60}$ However, unlike the other three countries, they were not in the top five of accepted abstracts. In the World Psycho-Oncology Congress, the world's largest conference on psychosocial aspects of cancer care, hosted in Denmark in 2004 and Italy 2006, 90\%-92\% of accepted abstracts were found to have first authors from HICs, and $0.3 \%$ of first authors were from the African 


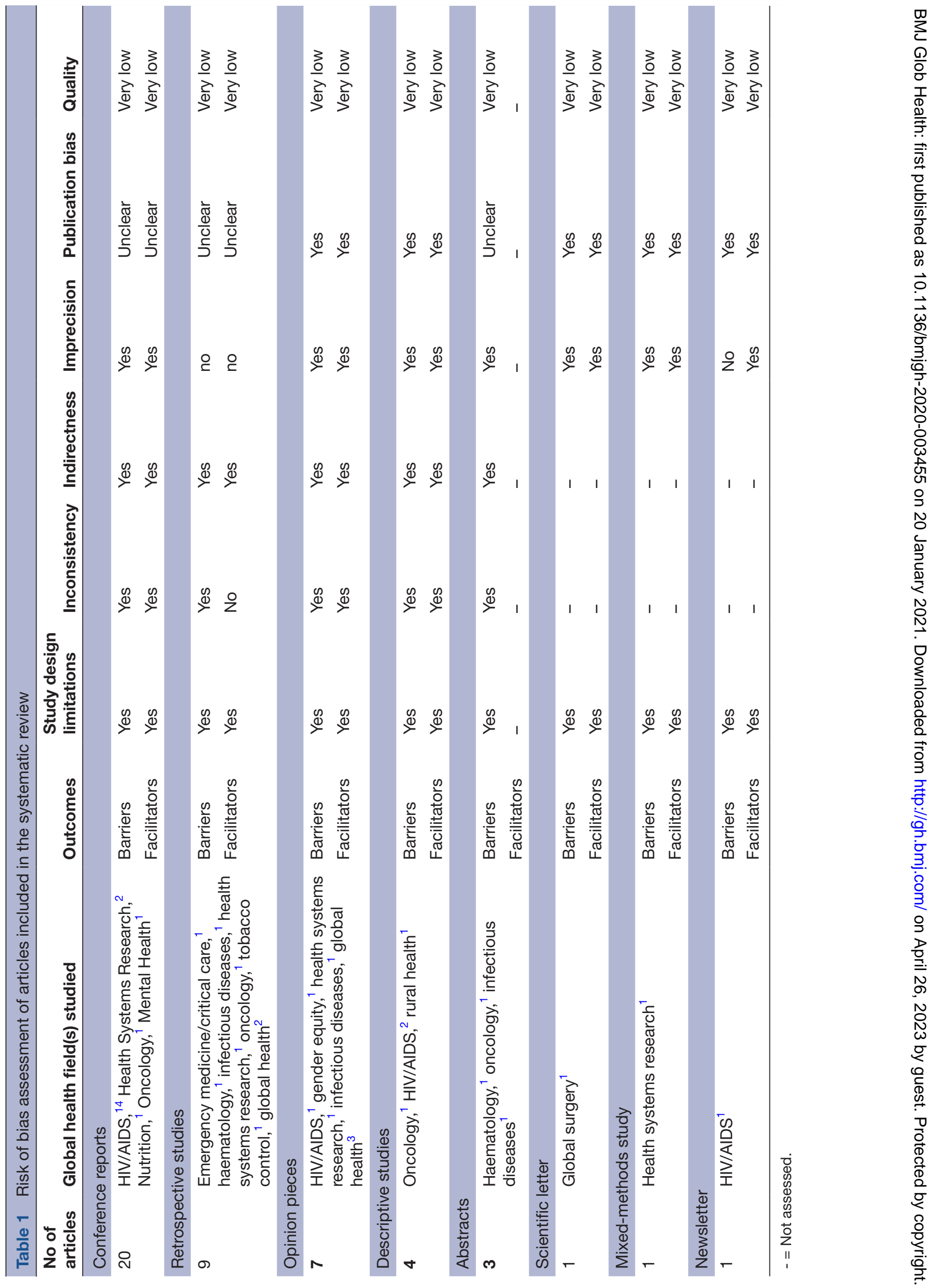




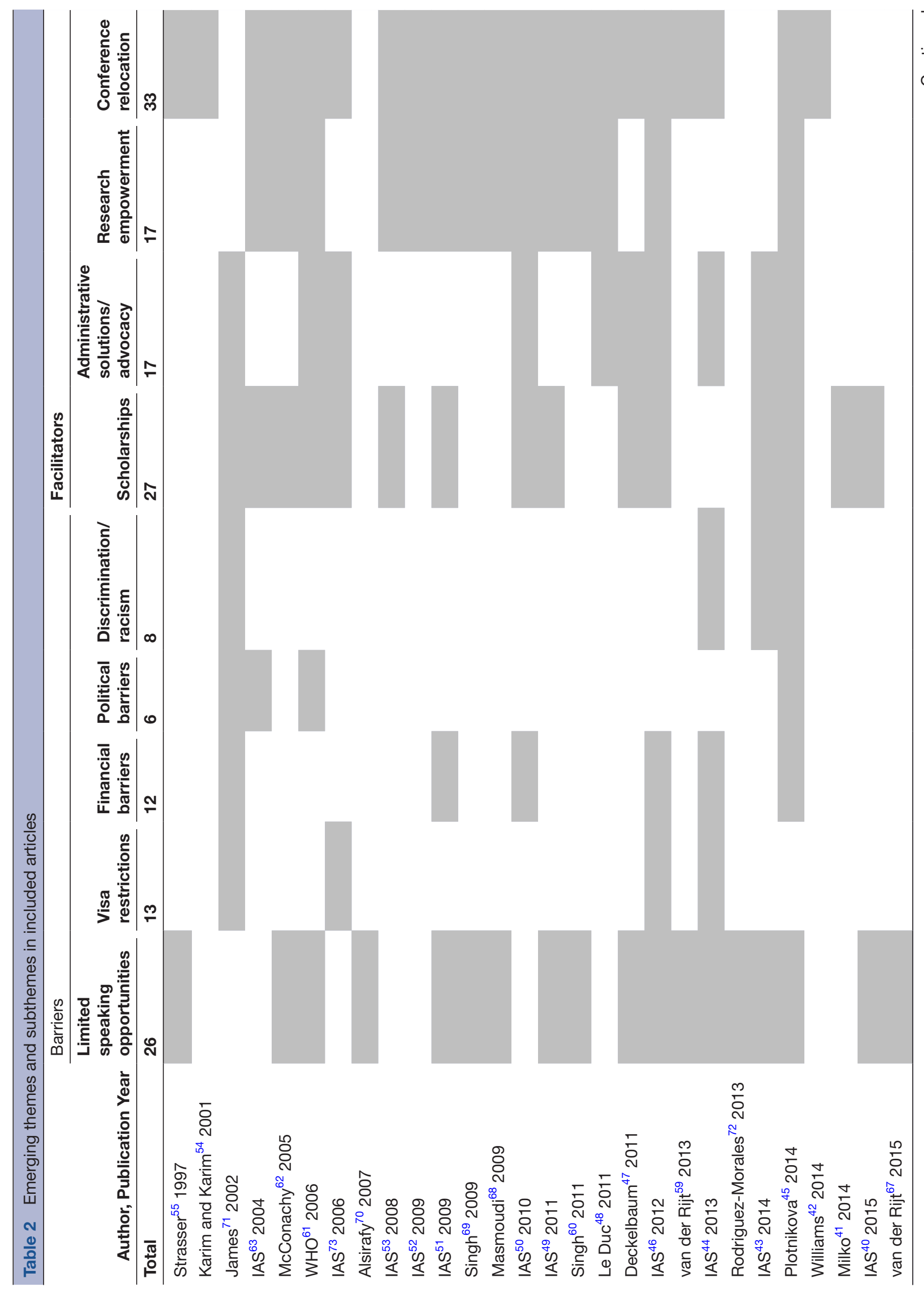




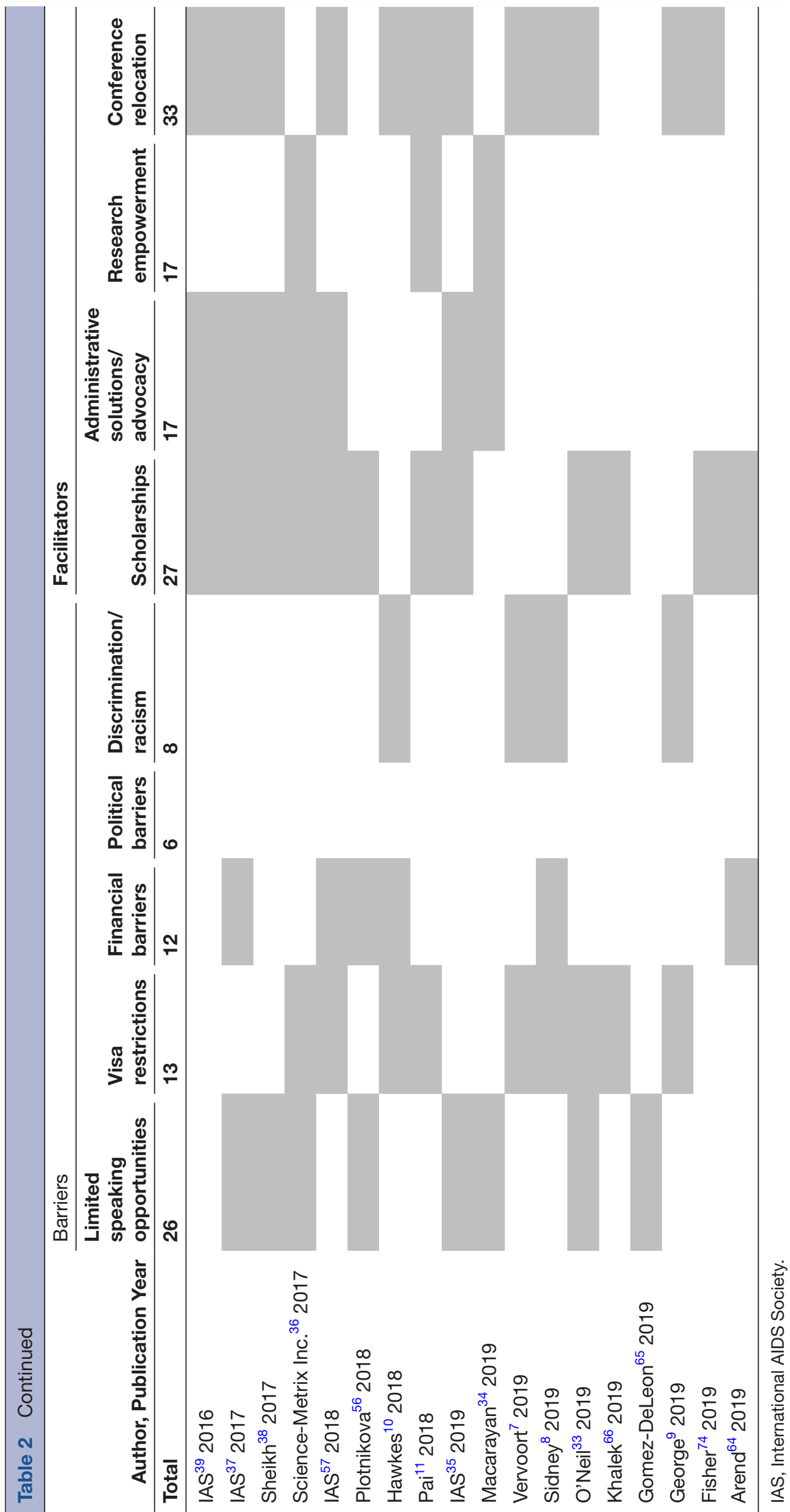




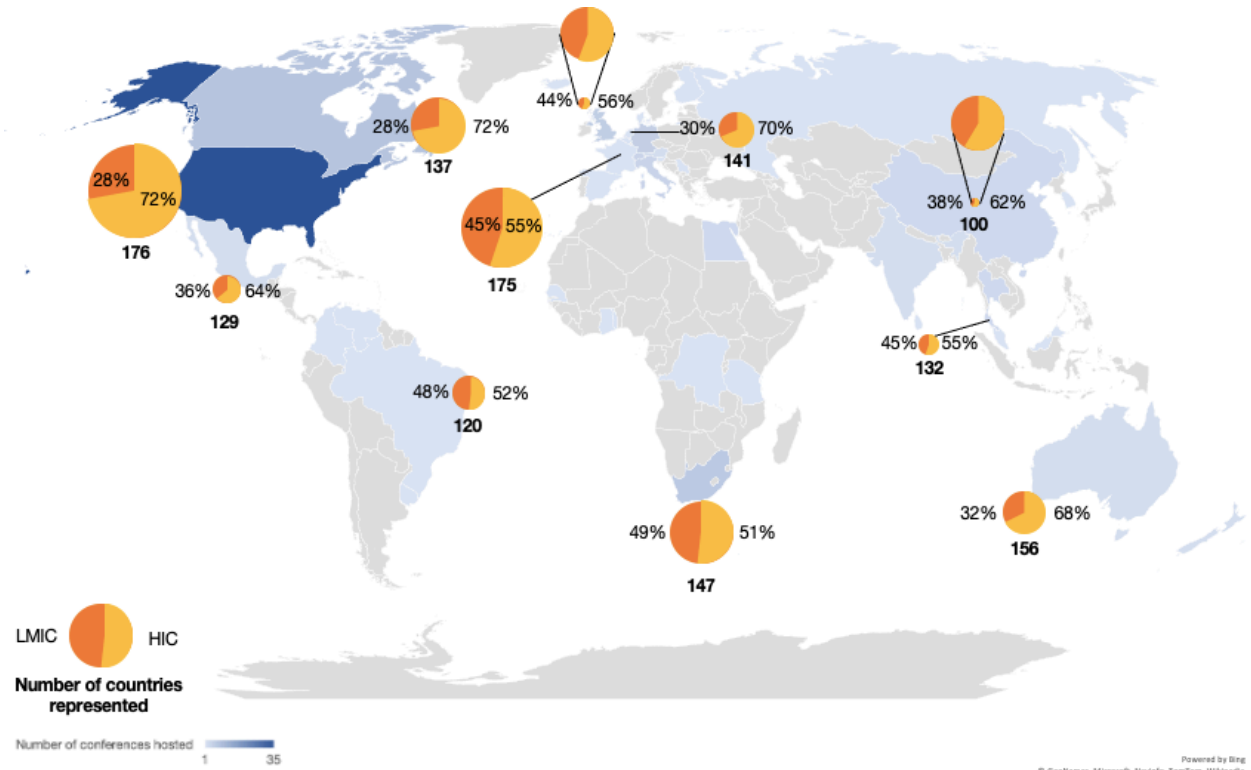

Figure 2 World map showing the distribution of global health conferences, the mean number of participants at conferences, the number of countries represented and the proportion of participants from low-income and middle-income countries (LMICs). The depth of the colour signifies the number of conferences hosted in the country. Only the conferences presenting data on the proportion of participants being from LMICs have data presented in the form of bubbles. The bubble size is proportional to the mean number of participants in the conference(s) hosted in each country. The two smallest bubbles have been magnified on the side for increased legibility. HIC, high-income country.

region, ${ }^{70}$ At the American Society of Clinical Oncology Annual Meeting, a USA-based conference that strives to reach clinical professionals from 'worldwide', authors from LMICs were represented in 15\% of abstracts generated from countries other than the USA. ${ }^{68}$ Four MICs (Brazil, China, India and Turkey) accounted for more than half of the LMIC contributions,. ${ }^{68}$ Abstracts from LMICs were less frequently scheduled for oral and poster presentations (1.4\% and $26.8 \%$ vs $8.8 \%$ and $52.8 \%$, respectively; $\mathrm{p}<0.001)$.

Financial barriers

Financial barriers to conference attendance were discussed in 12 articles. ${ }^{8} 103744-46505156576471$ Specific barriers included high conference registration rates, travel expenses and visa fees.

\section{Visa restrictions}

Visa restrictions were mentioned in 13 articles that unanimously reported LMIC attendees suffering disproportionally from complex visa processes and stringent requirements. ${ }^{4-8} 3033414354636870$ The visa process costs money and takes time, however, there is no guarantee that the visa will be granted..$^{8-10} 6671$

\section{Political barriers}

Political barriers were mentioned in four articles. $^{45616371}$ Examples of political barriers reported

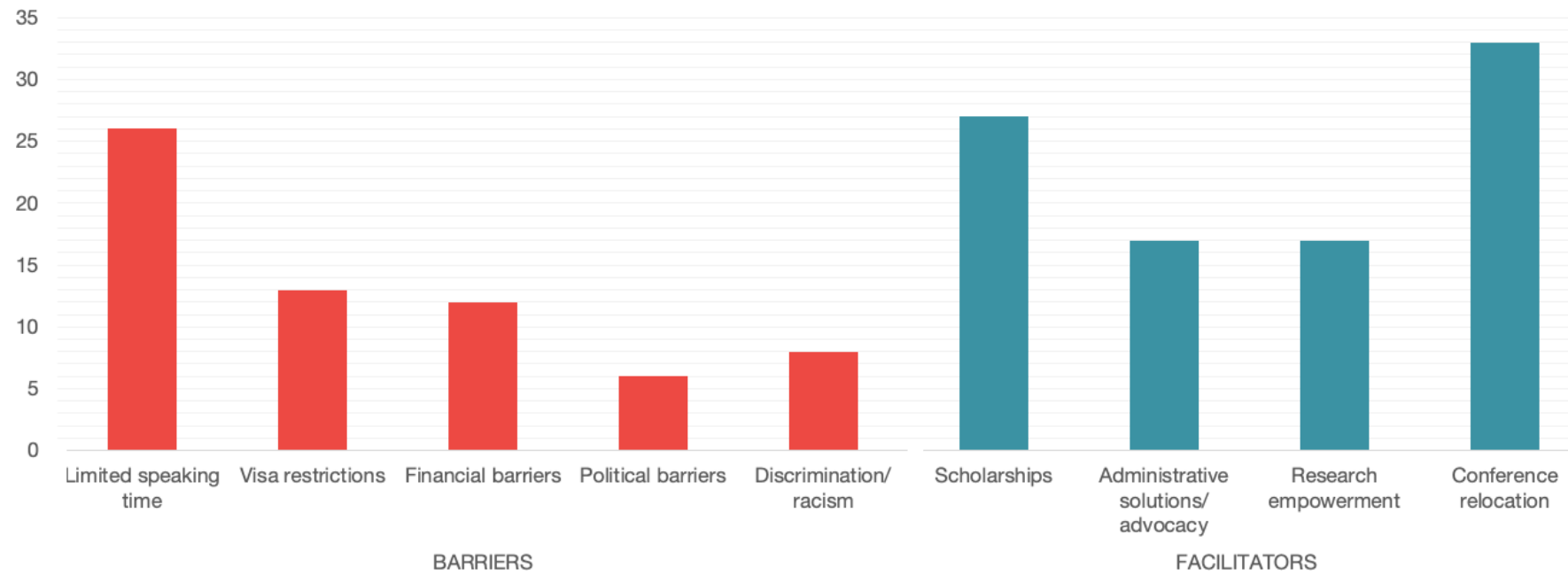

Figure 3 Bar charts showing the proportion of the different barriers and facilitators in regard to the number of articles on each barrier or facilitator. The $y$-axis represents the number of articles that discuss each barrier or facilitator to conference equity. 
were corruption at local embassies where embassy staff were asking for payments to get documents processed, ${ }^{71}$ regional terrorism and epidemic outbreaks, ${ }^{63}$ and the conference host country fearing LMIC attendees applying for refugee status on arrival, ${ }^{71}$

\section{Discrimination and racism}

Discrimination and racism were noted by seven articles with LMIC attendees expressing denied visas and barriers to attendance as one of many symptoms of a larger societal problem,. ${ }^{7-10} 444571$

\section{Facilitators}

The third theme was facilitators to conference attendance, which was reported in 43 articles $(93 \%){ }^{7-1133-575759-64666869717374}$ Four categories of facilitators were identified: relocating conferences to LMIC locations, scholarships, administrative/advocacy solutions and research empowerment.

\section{Scholarships}

Scholarships and other financial incentives were suggested in 27 articles. ${ }^{11} 33353638-414345-474950525356-5861-6466717374$ In a review by Arend and Bruijns of 20 international emergency and critical care conferences, $50 \%$ offered competitive travel scholarships and 36\% offered competitive scholarships for LMIC attendees specifically. ${ }^{64}$ As an alternative to scholarships, delegates called for reduced rates for LMIC attendees in three postconference surveys, ${ }^{33} 3540$ and two opinion pieces. ${ }^{1138}$ Among, international emergency medicine conferences, $41 \%$ offered daily rates, $36 \%$ offered discounted LMIC rates and $18 \%$ offered discounts for society members. ${ }^{64}$ Other articles suggested a holistic take-adopting a cost-saving mindset when planning the conference as a whole. ${ }^{471}$

\section{Administrative and advocacy solutions}

Administrative and advocacy solutions, mentioned in 18 articles, ${ }^{34-39} 43-48505357596171$ included working with local embassies to facilitate visa processes, using the conference website to publish information on which documents are needed for visa applications, ${ }^{71}$ and providing letters to facilitate visa applications,. ${ }^{48}$

\section{Research empowerment}

To address poor acceptance rates of submitted abstracts and limited speaking opportunities for LMIC researchers, research empowerment strategies were suggested in 17 articles. ${ }^{11} 3436454648-5360-636869$ The term 'research empowerment' was defined as 'knowledge transfer or access to research training that promotes research independence, first authorship and access and opportunity to apply for grant funding'. For the IAS Conference in 2009, an online programme to mentor LMIC researchers in abstract writing was initiated, which was continued in consecutive conferences. ${ }^{526069}$ In 2009, 50\% of all mentored abstracts were accepted of which 93\% were from LMICs. From 2009 to 2010 , the number of abstracts received for mentoring grew from 118 to 900 abstracts. Other initiatives were to include research in other languages than English and to develop information-sharing networks or programmes for mentoring and twinning. ${ }^{61}$

\section{Relocating conferences}

The overarching impact of the conference location was mentioned in 18 articles. $^{7835} 394245474951-55596062$ Increased representation of participants from the host region was seen in seven articles, with Western Europe and North America having high attendance rates, independent of geographic region,. ${ }^{3745495258-60}$ One article compared abstract submission rates from different regions between two conferences, noting no difference in top submitting countries for abstract submissions, despite variations in geographical location. ${ }^{62}$ Nine articles mentioned a regional adaptation or impact of the conference theme, such as sessions targeted to locally relevant topics, or noted that the topic of the conference was put on the national agenda, resulting in increased governmental commitments or sustained long-term projects in the host country. $3539444652-545774$

Considerations to host global health conferences in LMICs or 'visa-friendly' countries were suggested as a solution in 33 articles. . $^{-11} 3335$ 37-39 42 44-55 575759-63 68697374 Advantages and disadvantages, as perceived by both LMIC and HIC stakeholders at an individual and organisational level, of hosting global health conferences in LMICs were presented. Advantages were discussed in six articles. ${ }^{9} 3942545574$ Disadvantages were mentioned in two articles, ${ }^{42} 54$ and concerned the Ninth International Conference of African Organtion for Research and Training in Cancer in ${ }^{42}$ South Africa, 2013, and The 13th International AIDS Conference in South Africa, 2000. As an alternative to relocating the entire conference, IAS arranged conference 'hubs' in other parts of the world, ${ }^{46} 53$ with, for example, ${ }^{46}$ AIDS 2012 having 150 'hubs'. These events, which related to the conference themes and in some instances included live streams from the conference, reached over 6700 people from more than 41 countries. ${ }^{46}$

\section{DISCUSSION}

In this systematic review, we assessed factors, described as barriers or facilitators, that impact LMIC representation at global health conferences. Although conference equity has not been studied holistically before, phenomena mirroring our results, such as visa restrictions primarily affecting LMIC researchers and stakeholders, have been reported in global health and other arenas in society. ${ }^{7576}$ With recent calls to scrutinise historical and structural inequities in the global health field, particularly regarding the power relations between LMICs and HICs, ${ }^{22} 77$ and the paradigm shift in hosting conferences virtually during the COVID-19 pandemic, there may be momentum for global health to consider the role of conference equity. 
The included articles covered three decades of global health conferences that took place in 38 countries. The majority $(96 \%)$ of the conferences occurred in HICs or MICs, and 39\% of delegates were from LMICs. Two themes were found: barriers to conference equity and facilitators to conference equity. Attendance at most global health conferences is still inequitable with significant barriers for active participation for LMIC attendees resulting in disproportional HIC attendance and speaking opportunities. However, some conferences have implemented strategies to help overcome these barriers, such as scholarships, research empowerment programmes, or relocating the conference, striving towards global health conference equity.

Diversity in global health conferences ensures a wide range of perspectives and that global health efforts reflect the needs and realities of LMICs. Attendance at conferences is an opportunity for LMIC researchers to partake in the networking, capacity-building, professional growth necessary for career development and influence policymaking in global health. ${ }^{83} 36394445$ It also represents an opportunity for HIC researchers to gain from an increased diversity of perspectives. However, LMIC attendees are persistently under-represented at global health conferences, with LMIC attendees constituting only $39 \%$ of delegates. At the Conference of the Parties to the WHO Framework for Tobacco Control, Plotnikova et al found that $60 \%$ of LMIC delegates were from the national ministries of health and tobacco control focal points, compared with $42 \%$ of HIC delegates. ${ }^{45}$ This suggests that the limited LMIC representation has additional consequences and that representation from several sectors including civil society, government representatives and non-governmental organisations from LMICs is likely even further limited.

LMIC attendees face multiple barriers to attending global health conferences, with financial barriers constituting one set of important obstacles to conference equity. Costs associated with conference attendance tend to be higher for LMIC attendees as most global health conferences take place in Europe or the USA and various barriers prevent LMIC participants from registering or purchasing flight tickets early. ${ }^{8}$ In a study of registration costs at international emergency medicine conferences by Arend $e$ al, only 1 of the 20 conferences included, the African Conference on Emergency Medicine, offered 'equitable conference fees', calculated as registration rates adjusted for Purchasing Power Parity. ${ }^{64}$

If overcoming the first set of obstacles, financial barriers, visa restrictions remain a second major barrier. For the 2018 Women Leaders in Global Health Conference in the United Kingdom, visa applicants had to demonstrate an employment contract, a bank statement covering the previous 6 months, and an income tax return-conditions which could be hard for some LMIC attendees to meet, especially those coming on a travel scholarship. ${ }^{7678} 79$ Consequentially, 17 speakers and delegates were rejected visas and unable to attend the conference, to which the director of the London School of Hygiene and Tropical Medicine responded by writing to the Home Secretary sharing his concerns of visa barriers impacting global health. ${ }^{74}$ Previous literature indicates that visa barriers do not impact everyone equally - a 2018 report found that $34 \%$ of academics from Africa and $40 \%$ of academics from Asia had faced visa challenges, to be compared with 9\% of academics in Europe and North America, with the length of time needed to process applications being cited as the most common challenge ${ }^{80}$ Fears of LMIC attendees applying for refugee status on arrival in the country host of a conference was cited as a reason for rejecting visas, ${ }^{7}$ however, this fear has been proved to be unfounded. ${ }^{71}$ In addition to the academic literature assessed in this study, rejected visa applications for conference attendees from LMICs have been well described in multiple news articles and blog posts, indicating the depth and breadth of this issue. ${ }^{75-778182}$ The 'indignity' of the process was noted by Georg et al: you are confirmed a supplicant at the mercy of these faceless bureaucrats and left wondering whether you really want to go at all'. ${ }^{9}$ In response to denied visas to the $^{71}$ conference in Barcelona, Spain, LMIC researchers and stakeholders expressed that this may be a symptom of a larger societal problem of racism, where travellers from LMICs are not welcomed in Europe or the USA. ${ }^{71}$

To achieve conference equity, financial, geographical, political, discriminatory and visa-related barriers have to be mitigated-if not deconstructed entirely. Strategies to facilitate conference equity can be led both by conference organisers and conference attendees. For example, Sheikh et al suggested conference attendees could seize the power of social media to advocate for equity, for example, by 'calling out' panels with only HIC attendees. ${ }^{38}$

To achieve conference equity, addressing financial barriers will also be important. Various models for scholarships exist-including sponsorship models consisting of donations by peers and other delegates,${ }^{74}$ such as the 'Supadel' (support-a-delegate) scheme used by the African Conference on Emergency Medicine and the International Conference on Emergency Medicine since $2009{ }^{64}$ Other sources of scholarships include foundations, Ministries of Health and pharmaceutical companies. ${ }^{6674}$

Another possible facilitator is to carefully consider the location and timing of conferences. This could include arranging conferences in cheap or free university venues or to book hotel space in low season, which would otherwise be empty, allowing conferences to lower costs and maximise the number of scholarship awards. ${ }^{47} 71$ Pai, ${ }^{11}$ suggested relocating conferences to LMICs as a solution that could impact the tone of the conference:

Sitting in fancy hotels and resorts, it is easy to be disconnected from the reality of the [tuberculosis] epidemic which affects the poorest communities in [LMICs]. Every year, the richest people in the world meet at a ski mountain resort in Davos to talk about poverty. [Tuberculosis] must avoid this Davos syndrome. 
Hosting a global conference in an LMIC has substantial impact on both LMIC and HIC attendees and reflects the priorities of the conference organisers. For the AIDS 2016 conference, the authors suggested that the return of the conference to South Africa, after the landmark AIDS conference hosted there in 2000, was an opportunity to show the progress that had been made since the previous conference, with 'the backdrop of returning to South Africa after 16 years (building) a natural narrative on the progress made since the earlier days of the epidemic'. ${ }^{39}$ Similarly, hosting this conference in South Africa brought required contextual and cultural understanding with 'the success and spirit of the South African antiapartheid struggle further infused hope and vibrancy'. ${ }^{54}$ Hosting global health conferences in LMICs also adds the advantage of proximity to locations where the majority of the disease burden exists. This has been stated to help overcome the schism between research and affected communities as delegates at the AIDS 2000 conference 'experienced a true understanding of the devastation and pain caused by AIDS, ${ }^{54}$ Showcasing local culture through traditional dances, music, and art and visits to local centres working with the health matter in question were also highlighted as benefits. ${ }^{11} 435574$ Another advantage of hosting conferences in LMICs may be sustained local or regional impact; we term this phenomenon 'implementation effect'. ${ }^{46}$ One example of this was the University of KwaZulu-Natal in Durban, South Africa, where hosting the 13th International AIDS Conference led to the inauguration of an HIV/AIDS research chair, potentially leading to advancement of research at the university. ${ }^{54}$ Similarly, during AIDS 2012 in the USA, bringing awareness and commitment to the HIV/AIDS epidemic in the USA was a specific objective of the conference. ${ }^{46}$

Locating conferences in LMICs may also pose challenges. ${ }^{4254}$ First, LMIC conferences may not be exempt from barriers to accessibility, with some LMICs having strict visa processes ${ }^{83}$ and flights between LMICs, particularly in Africa, being few and notoriously expensive. ${ }^{84}$ For example, $51 \%$ of Africans need visas to travel to other countries, ${ }^{85} \mathrm{HIC}$ attendees may also perceive challenges, such as with the AIDS 2000 conference, boycott threats were made by senior scientists and academics regarding the South African government's stance on HIV/AIDS in the months leading up to the conference, and some questioned the ability of any LMIC to host the world's 'premier AIDS conference' ${ }^{54}$ Concerns were also raised about the quality of the conference programme, accommodation availability, specifically the lack of five-star hotels, and the high rate of criminality. ${ }^{54}$ Despite these challenges, it is critical conference organisers work with sponsors and local representatives to navigate the political climate and ensure conferences are held in diverse locations.

Importantly, simply increasing the number of LMIC attendees does not equate to conference equity. On the contrary, active participation is essential, yet LMIC attendees are frequently under-represented in speaking roles and research presentations. In academic conferences, researcher empowerment strategies can play a key role since limited research infrastructure, support and mentorship are known barriers to engaging in research, ${ }^{86}$ which, in consequence, may limit the opportunities to be receive active speaking roles in such conferences. Conference organisers can facilitate equity through using selection criteria to ensure diverse representation among speakers, ensuring access to active participation to those non-proficient in English, and using innovative programmes facilitating active participation in a nonhierarchical manner and by arranging pre-symposium activities such as regional events to increase the participation of previously underrepresented regions. 333638 Importantly, research empowerment strategies facilitate achieving conference equity; making conferences more equitable could also be another empowerment strategy by providing access and opportunities for LMIC attendees. ${ }^{36}$

Providing data on the demographics of global health conferences may be an important step in establishing conference equity. Publicly available conference reports, such as those by IAS and HSR, ${ }^{33} 35-3739-4143444649-5357626373$ detailing conference attendance demography (categorised by region, gender, age and affiliation), summaries of participant survey findings, and conference programme details including strategies undertaken to increase diverse representation (such as scholarships, mentorship programmes, and community engagement) can serve as a way for conferences to share best practices. It may also be beneficial in research endeavours and can help conferences create a baseline for implementing strategies that promote conference equity.

\section{Study limitations}

The majority of included articles were conference reports and retrospective studies, with specific global health conferences such as large HIV/AIDS conferences disproportionately represented, possibly skewing the study findings. It is unclear to what extent the results from one global health field or conference type may be extrapolated to other global health conferences of a different size, location or focus. The authors, holding a strong belief in conference equity, likely conferred an unconscious bias. To limit bias in our search results, we worked with an information specialist to develop the search strategy and did a complementary, standardised hand search of grey literature to identify non-academic literature from a wider selection of conferences.

Addressing the issue of conference equity holistically requires an intersectional perspective on accessibility and inclusion. The lack of consistent reporting of disaggregated data on attendance or speaking roles based on gender identity, age, ethnicity and ability prohibits detailed understanding of the accessibility of global health conferences. Persons with disabilities may face unique challenges in conference settings which can be overcome with thoughtful planning and providing support and resources to make the event accessible to 
all, including those with physical as well as audiovisual disabilities.

Due to the limited literature on this topic and the data heterogeneity, we were unable to perform a meta-analysis. Using the modified GRADE approach, the evidence in the articles included were all of very low quality. However, this tool was adapted to accommodate the range of literature in this study which may have compromised the validity of the tool and therefore the conclusions drawn. Despite these limitations, this study provides the foundation for further research on conference equity.

\section{CONCLUSION}

This review is the first study to date, to thoroughly describe the barriers and facilitators that influence LMIC representation at global health conferences. Our results show that conference inequity limits representation and hinders active participation by LMIC stakeholders at global health conferences. This results in missed opportunities for participation in decision making, networking, advocating, capacity building and professional career development. This is also a loss for HIC stakeholders who miss the chance to learn from LMIC attendees and to build and consolidate equitable bilateral partnerships. The inequities result from systemic barriers including cost of travel, visa processes and lower acceptance rates for research presentations. A recommended first step towards equity is for conference organisers to conduct independent conference equity evaluations and to publish this data in publicly available annual conference reports. Relocating conferences to LMICs, offering scholarships, and enabling LMIC researchers through mentorship can help overcome these barriers and take us one step closer to achieving conference equity.

\section{Author affiliations}

${ }^{1}$ Program in Global Surgery and Social Change, Harvard Medical School, Boston, Massachusetts, USA

${ }^{2}$ Center for Surgery and Public Health, Department of Clinical Sciences, Faculty of Medicine, Lund University, Lund, Sweden

${ }^{3}$ State University of Haiti Faculty of Medicine and Pharmacy, Port-au-Prince, Ouest, Haiti

${ }^{4}$ Medicine, Life Sciences \& Psychology Department, University of Warwick,

Coventry, UK

${ }^{5}$ McGill University Faculty of Medicine, Montreal, Québec, Canada

${ }^{6}$ Department of Neurosurgery, University of Kinshasa Faculty of Medicine, Kinshasa, Congo (the Democratic Republic of the)

${ }^{7}$ Department of General Surgery, Rutgers Robert Wood Johnson Medical School

New Brunswick, New Brunswick, New Jersey, USA

${ }^{8}$ Warwick Clinical Trials Unit, Warwick Medical School, Coventry, West Midlands, UK

Twitter Lotta Velin @VelinLotta, Jean-Wilguens Lartigue @jwlartigue, Anudari Zorigtbaatar @anudari.zorigtbaatar and Ulrick Sidney Kanmounye @ulricksidney

Acknowledgements The authors would like to thank Carol Mita from the Harvard Medical School Countway Library for advice on the search strategy.

Contributors LV: conceptualisation, design and validation of methodology, data collection, visualisation of tables and figures, formal analysis, writing of original draft and editing. J-WL: conceptualisation, data collection, visualisation of tables and figures, formal analysis, writing of original draft and editing. SAJ: conceptualisation, design and validation of methodology, reviewed the writing and editing. AZ: conceptualisation, data collection, visualisation of tables and figures, reviewed the writing and editing. USK: conceptualisation, data collection, reviewed the writing and editing. PT: conceptualisation, reviewed the writing and editing. MJ: conceptualisation, design and validation of methodology, supervision, reviewed the writing and editing.

Funding The authors have not declared a specific grant for this research from any funding agency in the public, commercial or not-for-profit sectors.

Map disclaimer The depiction of boundaries on this map does not imply the expression of any opinion whatsoever on the part of BMJ (or any member of its group) concerning the legal status of any country, territory, jurisdiction or area or of its authorities. This map is provided without any warranty of any kind, either express or implied.

\section{Competing interests None declared.}

Patient and public involvement statement Patients and the public were not involved in the development of the research question, choice of outcome measures, or the design and conduct of this systematic review.

Patient consent for publication Not required.

Provenance and peer review Not commissioned; external peer-reviewed.

Data availability statement All data relevant to the study are included in the article or uploaded as online supplemental information. No data are stored in a repository. No unpublished data are available following this review.

Supplemental material This content has been supplied by the author(s). It has not been vetted by BMJ Publishing Group Limited (BMJ) and may not have been peer-reviewed. Any opinions or recommendations discussed are solely those of the author(s) and are not endorsed by BMJ. BMJ disclaims all liability and responsibility arising from any reliance placed on the content. Where the content includes any translated material, BMJ does not warrant the accuracy and reliability of the translations (including but not limited to local regulations, clinical guidelines, terminology, drug names and drug dosages), and is not responsible for any error and/or omissions arising from translation and adaptation or otherwise.

Open access This is an open access article distributed in accordance with the Creative Commons Attribution Non Commercial (CC BY-NC 4.0) license, which permits others to distribute, remix, adapt, build upon this work non-commercially, and license their derivative works on different terms, provided the original work is properly cited, appropriate credit is given, any changes made indicated, and the use is non-commercial. See: http://creativecommons.org/licenses/by-nc/4.0/.

\section{ORCID iDs}

Lotta Velin http://orcid.org/0000-0002-1929-6011

Jean-Wilguens Lartigue http://orcid.org/0000-0001-9889-7976

Samantha Ann Johnson http://orcid.org/0000-0002-4716-1229

Anudari Zorigtbaatar http://orcid.org/0000-0002-5050-8967

\section{REFERENCES}

1 Mishra S. Do medical conferences have a role to play? sharpen the Saw. Indian Heart J 2016;68:111-3.

2 Smith CB, Rienner L. Politics and process at the United nations: the global dance, 2006.

3 Gopalan C, Halpin PA, Johnson KMS. Benefits and logistics of nonpresenting undergraduate students attending a professional scientific meeting. Adv Physiol Educ 2018;42:68-74.

4 Casad BJ, Chang AL, Pribbenow CM. The benefits of attending the annual biomedical research conference for minority students (ABRCMS): the role of research confidence. CBE Life Sci Educ 2016;15:ar46.

5 Christiaens G, Abegglen J, Rowley A. Nursing students' perceptions of a holistic nursing conference: empowerment, self-care, and application to practice. J Holist Nurs Off J Am Holist Nurses Assoc 2008;26:139-46.

6 Stephens S. Medical Conferences: "Should I Stay or Should I Go?" [Internet], 2019. Health eCareers. Available: https://www. healthecareers.com/article/medical-conferences-benefits-to-going [Accessed cited 2020 Nov 27].

7 Vervoort D. Dominique Vervoort: The visa conundrum in global health [Internet], 2019. Bmj opinion. Available: https://blogs.bmj. $\mathrm{com} / \mathrm{bmj} / 2019 / 06 / 21 /$ dominique-vervoort-the-visa-conundrum-inglobal-health/

8 Sidney U. Ulrick Sidney: Visas for global health events-too many are losing their seat at the table [Internet], 2019. Available: https:// blogs.bmj.com/bmj/2019/07/30/ulrick-sidney-visas-for-globalhealth-events-too-many-are-losing-their-seat-at-the-table/ 
9 George A, de Jong M. Visas: A Regressive Tax on LMICs [Internet], 2019. Health systems global. Available: https://www. healthsystemsglobal.org/blog/367/Visas-a-regressive-tax-on-LMICs. html

10 Hawkes N. British competitiveness at risk from visa system that rejects conference Delegates, warn scientists. BMJ 2018;363:k4779.

11 Pai M. TB Conferences: We Must Do Better [Internet], 2018. Nature microbiology community. Available: https://naturemicrobiologyco mmunity.nature.com/users/20892-madhukar-pai/posts/40361-tbconferences-we-must-do-better [Accessed cited 2020 Jun 22].

12 The World Bank. Population, total [Internet], 2018. Available: https:// data. worldbank.org/indicator/SP.POP.TOTL?locations=XO\&name desc $=$ false [Accessed cited 2020 Jun 22].

$13 \mathrm{Kim} \mathrm{JU}$, Oleribe O, Njie R, et al. A time for new north-south relationships in global health. Int J Gen Med 2017;10:401-8.

14 Hedt-Gauthier BL, Jeufack HM, Neufeld NH, et al. Stuck in the middle: a systematic review of authorship in collaborative health research in Africa, 2014-2016. BMJ Glob Health 2019;4:e001853.

15 Mbaye R, Gebeyehu R, Hossmann S, et al. Who is telling the story? A systematic review of authorship for infectious disease research conducted in Africa, 1980-2016. BMJ Glob Health 2019;4:e001855.

16 Nafade V, Sen P, Pai M. Global health journals need to address equity, diversity and inclusion. BMJ Glob Health 2019;4:e002018.

17 Global Health 5050. 2020 Global Health 50/50 Report [Internet], 2020. Available: https://globalhealth5050.org/2020report/

18 Scheiner A, Rickard JL, Nwomeh B, et al. Global surgery Pro-Con debate: a pathway to bilateral academic success or the BOLD new face of colonialism? J Surg Res 2020;252:272-80.

19 Horton R. Offline: is global health neocolonialist? The Lancet 2013;382:1690.

20 Farley J. Bilharzia: a history of imperial tropical medicine. Cambridge University Press, 2003.

21 Scott HH. A history of tropical medicine, vol. 841. vol II. Baltim Williams Wilkins Co, 1930.

22 Pai M. Global health still mimics colonial ways: here's how to break the pattern [Internet], 2019. The conversation. Available: https:// theconversation.com/global-health-still-mimics-colonial-ways-hereshow-to-break-the-pattern-121951 [Accessed 3 Sep 2020].

23 Kanmounye U, Zorigtbataar A, Velin L. Impact of US visa rejection rates and passport power on us global health conference attendance among low- and middle-income country researchers. In [Unpublished], 2019.

24 Campbell RM, Pleic M, Connolly $\mathrm{H}$. The importance of a common global health definition: how Canada's definition influences its strategic direction in global health. J Glob Health 2012;2:010301.

25 Herzig van Wees S, Holmer H. Global health beyond geographical boundaries: reflections from global health education. BMJ Glob Health 2020;5:e002583.

26 Taylor S. 'Global health': meaning what? BMJ Glob Health 2018;3:e000843.

27 Koplan JP, Bond TC, Merson MH, et al. Towards a common definition of global health. Lancet 2009;373:1993-5.

28 Moher D, Liberati A, Tetzlaff J, et al. Preferred reporting items for systematic reviews and meta-analyses: the PRISMA statement. PLoS Med 2009;6:e1000097.

29 Braun V, Clarke V. Using thematic analysis in psychology. Qual Res Psychol 2006;3:77-101.

30 The World Bank. World Bank Country and Lending Groups [Internet] Available: https://datahelpdesk.worldbank.org/knowledgebase/ articles/906519-world-bank-country-and-lending-groups [Accessed 4 May 2020].

31 World Health Organization. WHO regional groupings [Internet], 2017. Available: https://www.who.int/gho/publications/world health statistics/2017/EN_WHS2017_AnnexC.pdf?ua=1 [Accessed 4 May 2020].

32 Schünemann H, Brożek J, Guyatt G. GRADE handbook for grading quality of evidence and strength of recommendations [Internet], 2013. The grade Working group. Available: https://gdt.gradepro.org/ app/handbook/handbook.html\#h.9rdbelsnu4iy [Accessed 22 Jun 2020].

33 O'Neil. Evaluation of the Fifth Global Symposium on Health Systems Research [Internet], 2019. Available: https://healthsystemsglobal. org/reports/evaluation-of-the-fifth-global-symposium-on-healthsystems-research/ [Accessed Jun 22, 2020]

34 Macarayan EK, Balabanova D, Gotsadze G. Assessing the field of health policy and systems research using symposium Abstract submissions and machine learning techniques. Health Policy Plan 2019;34:721-31.

35 IAS. 10th IAS Conference on HIV Science Report [Internet], 2019. IAS. Available: https://www.iasociety.org/Web/WebContent/File/
ConfReports/IAS2019_conferencereport_2904.pdf [Accessed 22Jun 2020]

36 Science-Metrix Inc. Evaluation of the fourth global Symposium on health systems research. Montreal, Quebec, Canada: Science-Metrix Inc, 2017

37 IAS. IAS 2017 - 9th IAS Conference on HIV Science, Conference Report [Internet], 2017. IAS. Available: https://www.iasociety.org/ Web/WebContent/File/IAS2017_conference_report.pdf [Accessed 22 Jun 2020].

38 Sheikh K, Bennett SC, El Jardali F, et al. Privilege and inclusivity in shaping global health agendas. Health Policy Plan 2017;32:303-4.

39 IAS. AIDS 2016 Conference Report [Internet], 2016. IAS. Available: http://www.aids2016.org/Portals/0/File/AIDS2016_evaluation_report. pdf?ver=2017-04-05-170315-470 [Accessed 22 Jun 2020].

40 IAS. 8th IAS Conference on HIV Pathogenesis, Treatment and Prevention Evaluation Report [Internet], 2015. Available: https:// www.iasociety.org/Web/WebContent/File/IAS2015_Evaluation_ Report.pdf [Accessed 22 Jun 2020].

41 Milko E, Wu D, Neves J, et al. Second global Symposium on health systems research: a conference impact evaluation. Health Policy Plan 2015;30:612-23.

42 Williams CK, Cristina Stefan D, Rawlinson F. The African organisation for research and training in cancer and its conferences: a historical perspective and highlights of the ninth International Conference, Durban, South Africa, 21-24 November 2013. Ecancermedicalscience, 2014: 8. 396.

43 IAS. AIDS 2014 - 20th International AIDS Conference, Evaluation Report [Internet], 2014. IAS. Available: https://www.iasociety.org/ Web/WebContent/File/AIDS2014_Evaluation_Report_Dec2014.pdf [Accessed 22 Jun 2020].

44 IAS. 7th IAS Conference on HIV Pathogenesis, Treatment and Prevention Evaluation Report [Internet], 2013. IAS. Available: https:// www.iasociety.org/Web/WebContent/File/IAS2013 Evaluation Report.pdf [Accessed 22 Jun 2020].

45 Plotnikova E, Hill SE, Collin J. The 'diverse, dynamic new world of global tobacco control'? An analysis of participation in the Conference of the Parties to the WHO Framework Convention on Tobacco Control. Tob Control 2014;23:126-32.

46 IAS. AIDS 2012 - XIX International AIDS Conference, Evaluation Report [Internet], 2012. IAS. Available: https://www.iasociety.org/ Conferences/Previous-Conferences/Timeline [Accessed 22 Jun 2020]

47 Deckelbaum Det al. Global health conferences: Are they truly "global"? The Bethune Round Table paradigm for promoting global surgery. Can J Surg 2011;54:422-9.

48 Le Duc JW, Deacetis J. Review and assessment of the American Society of tropical medicine and hygiene travel awards program, 1991-2010. Am J Trop Med Hyg 2011;85:409-13.

49 IAS. 6th IAS Conference on HIV Pathogenesis, Treatment and Prevention Evaluation Report [Internet], 2011. IAS. Available: https:// www.iasociety.org/Web/WebContent/File/IAS2011 Evaluation Report.pdf [Accessed 22 Jun 2020].

50 IAS. AIDS 2010 - XVIII International AIDS Conference Evaluation Report [Internet], 2010. IAS. Available: https://www.iasociety.org/ Web/WebContent/File/AIDS2010_evaluation_report.pdf [Accessed 22 Jun 2020]

51 IAS, 5th IAS Conference on HIV Pathogenesis, Treatment and Prevention Evaluation Report [Internet], 2009. IAS. Available: https://www.iasociety.org/Web/WebContent/File/IAS\%202009\% 20Evaluation\%20Report.pdf [Accessed 22 Jun 2020].

52 IAS. Evaluation report xvii international aids conference, aids 2008 [Internet], 2009. IAS. Available: https://www.iasociety.org/Web/ WebContent/File/AIDS\%202008\%20Evaluation\%20Report.pdf [Accessed 22 Jun 2020].

53 IAS, 4th IAS Conference on HIV Pathogenesis, Treatment and Prevention [Internet], 2008. IAS. Available: https://www.iasociety.org/ Web/WebContent/File/IAS2007_evaluation_report.pdf [Accessed 22 Jun 2020].

54 Abdool Karim SS, Abdool Karim Q. Breaking the silence, one year later: reflections on the Durban conference. AIDS Clin Care 2001;13:70:63-5

55 Strasser R. From Shanghai to Durban: international rural health conferences. Aust J Rural Health 1997;5:165-8.

56 Plotnikova E, Hill SE, Wright A, et al. Towards 'a balanced delegation' or enhancing global health governance? Analysis of parties' participation in the Conference of the Parties to WHO Framework Convention on Tobacco Control. Tob Control 2019;28:636-42.

57 IAS. AIDS 2018 - 22nd International AIDS Conference, Conference Report [Internet], 2018. IAS. Available: http://www.aids2018.org/ Web/WebContent/File/aids2018/AIDS2018 Conference\%20Report. pdf [Accessed 22 Jun 2020]. 
58 IAS. Report of the Evaluation of the XVI International AIDS Conference [Internet], 2017. IAS. Available: https://www.iasociety. org/Web/WebContent/File/Old/PDF/1339.pdf [Accessed 22 Jun 2020].

59 van der Rijt T, Pang T. 'How 'global' is 'global health'? Determining the geographical diversity of global health thinkers. Glob Health Gov 2013;VII, No 1:20-37.

60 Singh G. An online Abstract mentoring programme for junior researchers and healthcare professionals. Distance Education 2011;32:229-42.

61 World Health Organization, Food And Agriculture Organization of the United Nations. Enhancing developing country participation in FAO/ WHO scientific advice activities. FAO Food Nutr Pap 2006;88:1-36.

62 McConachy D. 3rd IAS Conference on HIV Pathogenesis and Treatment Evaluation Report [Internet], 2005. IAS. Available: https:// www.iasociety.org/Web/WebContent/File/IAS_2005_Evaluation_ Report.pdf [Accessed 22 Jun 2020].

63 IAS. Report on the xv international aids conference [Internet], 2004. IAS. Available: https://www.iasociety.org/Web/WebContent/File/Old/ PDF/BangkokReport.pdf [Accessed 22 Jun 2020].

64 Arend M-E, Bruijns SR. Disparity in conference registration cost for Delegates from low- and middle-income backgrounds. Afr J Emerg Med 2019:9:156-61.

65 Gómez-De León A, Colunga Pedraza PR, Tarín Arzaga LdelC, et al. Contributions to global hematology from low and middle-income countries: insights from ash 2018. Blood 2019;134:2123.

66 Khalek ER, Afungchwi GM, Beltagy ME, et al. Highlights from the 13th African continental meeting of the International Society of paediatric oncology (SIOP), 6-9 March 2019, Cairo, Egypt. Ecancermedicalscience 2019;13:932.

67 van der Rijt T, Pang (Pangestu) T. Governance within the World Health Assembly: A 13-year analysis of WHO Member States' contribution to global health governance. Health Policy 2015;119:395-404.

68 Masmoudi A. The contribution of limited-resource countries to the American Society of clinical oncology annual meetings. Int J Clin Oncol 2009;14:442-6.

69 Singh G. Online Abstract mentoring for inducting early career HIV researchers into scientific literacy practices: experiences from the International AIDS conferences. 1, 2009.

70 Alsirafy S, Al-Shahri M, Mousa S. Contribution of researchers from low and middle-income countries to the last two world congresses of psycho-oncology. Psychooncology 2007;16:S76.

71 James JS. Barcelona: visa barriers may disrupt conference. AIDS Treat News 2002:4-5.

72 Rodriguez-Morales AJ, Tobon-García D. P370 who is invited? A bibliometric analysis of the profiles of speakers at international and national congresses on infectious diseases. Int $J$ Antimicrob Agents 2013;42:S159

73 IAS. AIDS 2006 - The 16th International AIDS Conference [Internet], 2006. Available: https://www.iasociety.org/Web/WebContent/File/ Old/PDF/1339.pdf [Accessed 22 Jun 2020].
74 Fisher J, Chandra P. Reflections on the first conference of the International Marcé Society for perinatal mental health convened in India, a middle-income country. Arch Womens Ment Health 2019;22:637-40.

75 BBC News. Canada refuses visas to over a dozen African Al researchers, 2019. Available: https://www.bbc.com/news/world-uscanada-50426774 [Accessed 22 Jun 2020].

76 The Guardian. Who voices alarm as academics denied visas to visit UK conference, 2018. Available: https://www.theguardian.com/uknews/2018/oct/09/who-voices-alarm-academics-denied-visas-tovisit-uk-conference [Accessed 22 Jun 2020].

77 Green A. The activists trying to "decolonize" global health. DevEx [Internet], 2019. Available: https://www.devex.com/news/theactivists-trying-to-decolonize-global-health-94904

78 Piot P. Current visa restrictions a threat to UK establishing itself as a global hub for health and science [Internet], 2018. London Schoo of Hygiene \& Tropical Medicine. Available: https://www.lshtm.ac. uk/newsevents/expert-opinion/current-visa-restrictions-threat-ukestablishing-itself-global-hub-health

79 Edwards S, Watters L. Outrage after visas denied for UK global health conference, 2018. DevEx [Internet]. Available: https://www. devex.com/news/outrage-after-visas-denied-for-uk-global-healthconference-93821

80 Mclnroy GR, Lichten CA, loppolo B. International Movement and Science - A survey of researchers by the Together Science Can campaign [Internet], 2018. Rand Corporation. Available: https:// www.rand.org/pubs/research_reports/RR2690.html\#related [Accessed 1 Sep 2020].

81 Global Development Institute. Visa rejection for African experts hits GDI conference. The University of Manchester Global Development Institute Blog [Internet], 2019. Available: http://blog.gdi.manchester. ac.uk/visa-rejections-for-african-experts-hits-gdi/

82 Wise J. US denied visas to women trying to participate in UN women's conference: report. The Hill [Internet], 2019. Available: https://thehill.com/policy/international/435126-us-denied-visas-tointernational-women-trying-to-participate-in-un

83 Czaika M, de Haas H, Villares-Varela M. The global evolution of travel visa regimes. Popul Dev Rev 2018;44:589-622.

84 Fortin J. African Air Travel: Why Are Airlines In Africa So Expensive, Unsafe And Impossible To Navigate. IB Times [Internet], 2013. Available: https://www.ibtimes.com/african-air-travel-why-areairlines-africa-so-expensive-unsafe-impossible-navigate-1234609 [Accessed 24 Nov 2020].

85 African Development Bank Group, African Union. Africa Visa Openness Report 2018 [Internet], 2018. Available: https://www. afdb.org/fileadmin/uploads/afdb/Documents/Generic-Documents/ VisaOReport2018_R15jan19.pdf [Accessed 24 Nov 2020].

86 Lescano AG, Cohen CR, Raj T, et al. Strengthening mentoring in lowand middle-income countries to advance global health research: an overview. Am J Trop Med Hyg 2019;100:3-8. 